Check for updates

Cite this: RSC Adv., 2017, 7, 50571

\title{
30-Fold efficiency enhancement achieved in the perovskite light-emitting diodes $\dagger$
}

\author{
Xing-Juan Ma, Zhi-Qiang Wang, Zi-Yang Xiong, Yue Zhang, Fu-Xing Yu, Ping Chen, \\ Zu-Hong Xiong and Chun-Hong Gao (D)*
}

Efficient cesium lead halide perovskite light-emitting diodes (PeLEDs) are demonstrated using nearly 100\% coverage of $\mathrm{CsPbBr}_{3}$ film as the emitter. The PeLEDs with only a pumping away process deposited from equimolar $\mathrm{PbBr}_{2}-\mathrm{CsBr}$ exhibit more than 30 fold electroluminescent (EL) performance improvement compared to the ones with both pumping away and annealing processes. And to further improve the $\mathrm{EL}$ performance, the molar ratio of $\mathrm{PbBr}_{2}$ to $\mathrm{CsBr}$ is optimized. $\mathrm{CsBr}$-rich $\mathrm{PeLEDs}\left(\mathrm{PbBr}_{2}: \mathrm{CsBr}=1: 1.2\right)$ show longer stability and better EL performance with maximum luminance of $5046 \mathrm{~cd} \mathrm{~m}^{-2}$, maximum current efficiency of $3.25 \mathrm{~cd} \mathrm{~A} \mathrm{~A}^{-1}$, maximum external quantum efficiency (EQE) of $0.85 \%$. The physical mechanism to the enhanced EL performance in the PeLEDs with only pumping away can be attributed to three factors: better coverage rate and smoother surface which reduce current leakage, smaller grain size which can spatially limit the diffusion length of excitons or charge carriers and decrease the possibility of exciton dissociation into carriers, and increased $\mathrm{CsBr}$ content of the perovskite precursor solution which may reduce the nonradiative defect densities.

Received 27th August 2017 Accepted 20th October 2017

DOI: $10.1039 / c 7 r a 09484 a$

rsc.li/rsc-advances cesium lead halide perovskite films. ${ }^{11-23}$ The first way is to prepare perovskite quantum dot films from dispersion of presynthesized perovskite colloidal nanocrystals..$^{12-18}$ The Kovalenko's method is involved to form the pre-synthesized perovskite colloidal nanocrystals, which needs the protection of $\mathrm{N}_{2}$ and a high reaction temperature ranged from $100{ }^{\circ} \mathrm{C}$ to $200{ }^{\circ} \mathrm{C}^{24,25}$ The other way is to obtain perovskite films directly from a perovskite precursor solution. ${ }^{19-22}$ The perovskite precursor solution is gained by dissolving both $\mathrm{CsBr}$ and $\mathrm{PbBr}_{2}$ in organic solvent such as dimethyl sulphoxide (DMSO), which is more simple than the Kovalenko's method. Moreover, the film deposited via the first way is relatively poor in film coverage due to the insolubility of the perovskite nanoparticle in toluene, and relatively poor conductivity caused by commonly used insulated long-chain surface ligands (such as oleic acid and oleylamine). ${ }^{14}$ Thus, the second way is used in this work.

Although the post-treatment processes to the all-inorganic perovskite films deposited via the above two methods are different, in most cases, researchers are used to annealing the perovskite films in order to make the films crystallize and the organic solvent volatilize faster to obtain high quality perovskite films with good coverage. ${ }^{13,16,19,20}$ To date, for the annealed films formed via the first way, the best reported neat $\mathrm{CsPbBr}_{3}$ quantum dots (QDs) PeLEDs are fabricated from films annealed at $90{ }^{\circ} \mathrm{C}$ for $5 \mathrm{~min}$ in glove box, ${ }^{13}$ showing a maximum luminance of $1698 \mathrm{~cd} \mathrm{~m}^{-2}$ for equimolar $\mathrm{PbBr}_{2}-\mathrm{CsBr}$ ones, and 3853 $\mathrm{cd} \mathrm{m}{ }^{-2}$ for CsBr-rich ones $\left(\mathrm{PbBr}_{2}: \mathrm{CsBr}=1: 2\right)$. While for the films without annealing formed via the first way, the best reported one is just dried in air for $10 \mathrm{~min}^{2}$, exhibiting maximum
School of Physical Science and Technology, MOE Key Laboratory on Luminescence and Real-Time Analysis, Southwest University, China.E-mail: gch0122@swu.edu.cn

$\dagger$ Electronic supplementary information (ESI) available. See DOI: 10.1039/c7ra09484a 
luminance of $2335 \mathrm{~cd} \mathrm{~m}^{-2}$ for the equimolar $\mathrm{PbBr}_{2}-\mathrm{CsBr}$ ones. However, for the annealed film via the second way, the best reported neat equimolar (CsBr-rich) $\mathrm{CsPbBr}_{3} \mathrm{PeLEDs}$ are fabricated from films annealed at $70{ }^{\circ} \mathrm{C}$ for $5 \mathrm{~min}\left(70{ }^{\circ} \mathrm{C}\right.$ for $\left.10 \mathrm{~min}\right)$ in glove box, ${ }^{20,21}$ showing a maximum luminance of $666 \mathrm{~cd} \mathrm{~m}^{-2}$ $\left(4800 \mathrm{~cd} \mathrm{~m}^{-2}\right)$. To improve the luminance, Wei et al. ${ }^{22}$ developed the third way by firstly obtaining $\mathrm{CsPbBr}_{3}$ powder via adding CsBr aqueous solution dropwise to the $\mathrm{PbBr}_{2}-\mathrm{HBr}$ solution, and secondly dissolving the as-prepared $\mathrm{CsPbBr}_{3}$ powder in DMSO, and finally depositing by one-step spin-coating, and obtaining a highest maximum luminance of $7276 \mathrm{~cd} \mathrm{~m}^{-2}$ for CsBr-rich ones $\left(\mathrm{PbBr}_{2}: \mathrm{CsBr}=1: 1.4\right)$. However, the post-treatment process of the $\mathrm{CsPbBr}_{3}$ film is not mentioned in their report and the preparation of the perovskite precursor solution is complicated.

In this paper, we found that the method of pumping away the solvent may be a better choice to make the solvent volatilize quickly and get high quality neat all-inorganic cesium lead halide perovskite $\mathrm{CsPbBr}_{3}$ films than the method employing annealing process after pumping away process. The PeLEDs with neat $\mathrm{CsPbBr}_{3}$ film gained by only pumping away method after one-step spin-coating, achieve maximum luminances of $3285 \mathrm{~cd} \mathrm{~m}^{-2}$ and $5046 \mathrm{~cd} \mathrm{~m}^{-2}$, maximum current efficiencies of $1.13 \mathrm{~cd} \mathrm{~A}^{-1}$ and $3.25 \mathrm{~cd} \mathrm{~A}^{-1}$, maximum external quantum efficiency (EQE) of $0.29 \%$ and $0.85 \%$ from the equimolar $\mathrm{PbBr}_{2}-$ $\mathrm{CsBr}$ and $\mathrm{CsBr}-$ rich $\left(\mathrm{PbBr}_{2}: \mathrm{CsBr}=1: 1.2\right)$ precursor solutions, respectively, which is among the best results based on neat $\mathrm{CsPbBr}_{3} \mathrm{PeLEDs}$ reported so far. Our results offer a facile method to achieve highly efficient PeLEDs by just pumping away after one-step spin-coating at room temperature.

\section{Experimental methods}

\subsection{Material and perovskite $\mathrm{CsPbBr}_{3}$ precursor}

Poly(3,4-ethylenedioxythiophene): $\operatorname{poly}(p$-styrene sulfonate) (PEDOT:PSS, Clevios AI 4083) was bought from Heraeus (Germany). The $2,2^{\prime}, 2^{\prime \prime}$-(1,3,5-benzinetriyl)-tris(1-phenyl-1- $H$-benzimidazole) (TPBi), 8-hydroxyquinolinato lithium (Liq), and aluminum (Al) were bought from Suzhou Fangsheng Photoelectricity Shares Co, Ltd and their purity are larger than 99\%. The perovskite $\mathrm{CsPbBr}_{3}$ precursor solution is obtained by dissolving both $\mathrm{PbBr}_{2}$ and $\mathrm{CsBr}$ (Xi'an Polymer Light Technology Corp., $>99.99 \%$ ) with molar ratios of $1: 1$ in DMSO (Alfa-Aesar, $>99.99 \%$ ) solvent with a concentration of $10 \mathrm{wt} \%$ under constant stirring larger than 12 hours.

\subsection{Device fabrication}

The pre-treated ITO-coated glass substrates, with a sheet resistance of $\sim 15 \Omega \mathrm{sq}^{-1}$, were sequentially pre-cleaned by acetone, ethanol, and deionized water and dried by oven. After ultraviolet ozone treatment for $5 \mathrm{~min}$, PEDOT:PSS was spin-coated on the ITO surface at $4500 \mathrm{rpm}$ for $40 \mathrm{~s}$ and then annealed at $120^{\circ} \mathrm{C}$ for $20 \mathrm{~min}$. Then, the substrates were transferred into a nitrogenfilled glove box. Next, the $\mathrm{CsPbBr}_{3}$ film was formed on the PEDOT:PSS by one-step spin-coating from $\mathrm{CsPbBr}_{3}$ precursor solution at $4000 \mathrm{rpm}$ for $60 \mathrm{~s}$ with different post-treatment processes. And then, TPBi $(65 \mathrm{~nm})$, Liq $(2.5 \mathrm{~nm})$, and $\mathrm{Al}$ $(120 \mathrm{~nm})$ cathode were evaporated on top of $\mathrm{CsPbBr}_{3}$ perovskite film by utilizing a LN-1103SC vacuum thermal depositing system from Shenyang Vacuum Technology Research Institute, where TPBi, Liq/Al are used as an electron transport layer and a bilayer cathode, respectively. The active area of each device was $2 \times 3 \mathrm{~mm}^{2}$ which is defined through a shadow mask. All devices were sealed with glass covers in glove box under the protection of $\mathrm{N}_{2}$.

\subsection{Measurements and characterization}

The top-view and cross-section images were taken with a scanning electron microscopy (SEM) system (JEOL, JSM-7100F). The absorption, PL spectra and time-resolved PL spectra were obtained by UV-Vis spectrophotometer (Shimadzu UV-2600) and fluorescence spectrometer (Folurolog 3), respectively. The atomic force microscope (AFM) images and XRD pattern were obtained by Cypher AFM (Cypher S) and X-ray diffractometer (XRD, TD-3500), respectively. The EL performance and stability of PeLEDs were recorded with a LED testing system including Keithley 2400, calculated Si photodiode (Photoelectric Instrument Factory of Beijing Normal University, ST-86LA), and Photo Research SpectraScan photometer (PR 670).

\section{Results and discussion}

\subsection{Film preparation and surface morphology}

The modified and reference neat $\mathrm{CsPbBr}_{3}$ films are obtained by one-step spin-coating from $10 \mathrm{wt} \% \mathrm{CsPbBr}_{3}$ in DMSO solution (shown in Fig. 1a and b). The modified $\mathrm{CsPbBr}_{3}$ film is acquired without annealing but only pumping away (Fig. 1c), while the reference $\mathrm{CsPbBr}_{3}$ film is annealed at $70{ }^{\circ} \mathrm{C}$ for $5 \mathrm{~min}$ after pumping away (the top-view SEM images for the optimization of annealing condition can be found in ESI Fig. S1†). And the pumping away is a method to get $\mathrm{CsPbr}_{3}$ perovskite film by pumping the solvent component of the precursor film in the transfer chamber of the glove box for $20 \mathrm{~min}$ at room temperature after the spin-coating process as shown in Fig. 1c. The pumping away system is comprised of a transfer chamber belonging to a glove box and attached by a mechanical pump. When the mechanical pump is open, the solvent of the precursor film will be pumped away. From the top view SEM images of the neat $\mathrm{CsPbBr}_{3}$ films, it can be found that the coverage of the modified film (Fig. 1d) is improved to $91.1 \%$ compared to the reference film (Fig. 1e) of $76.3 \%$ (estimated from SEM images by using Image software), and the average grain size is reduced to $\sim 100 \mathrm{~nm}$ compared to that of the reference film of $\sim 110 \mathrm{~nm}$. Higher coverage and smaller grains suggest that better EL performance can be achieved in the modified film based PeLEDs. In Fig. 1f, similar absorption spectra shapes are demonstrated in both modified and reference neat $\mathrm{CsPbBr}_{3}$ films with absorption band edges of $539 \mathrm{~nm}$ and $542 \mathrm{~nm}$, respectively. From the PL spectra in Fig. 1f, it suggests that the both modified and reference neat $\mathrm{CsPbBr}$ films have the same emission peaks (520 nm) and same FWHM ( $\sim 18 \mathrm{~nm})$. However, the modified neat $\mathrm{CsPbBr}_{3}$ film exhibits 
(a)

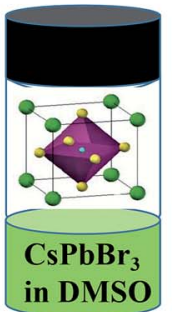

(b)

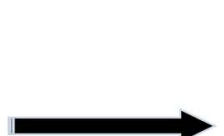

- $\mathbf{P b}$

- $\mathrm{Br}$

Cs
One-Step Spin-Coating

in Glove-Box

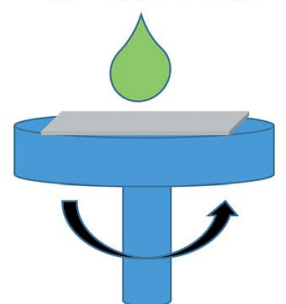

(c)

\section{Pumping Away} (-1.0 bar)

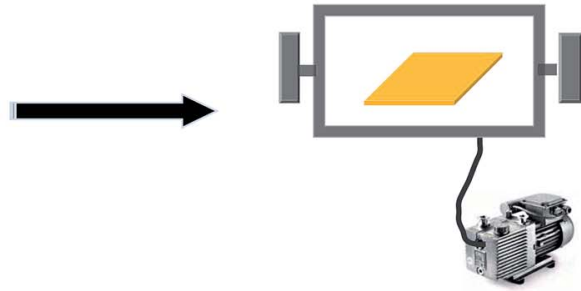

(d)

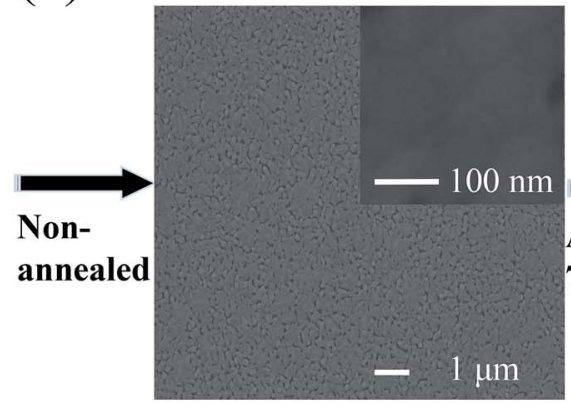

(e)

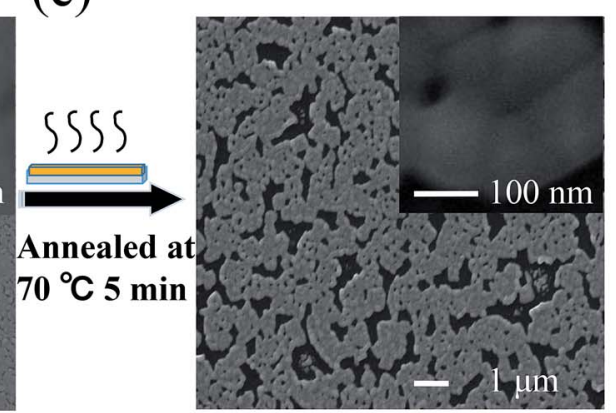

(f)

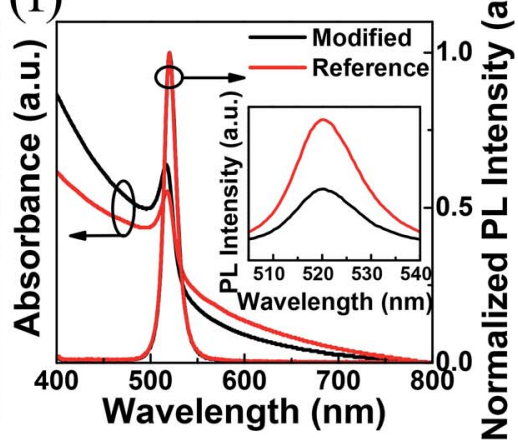

Fig. 1 The schematic diagram of (a) preparation of $10 \mathrm{wt} \% \mathrm{CsPbBr}_{3}$ in DMSO precursor solution, (b) one-step spin-coating method, (c) pumping away method, (d) the top-view SEM image of modified neat $\mathrm{CsPbr}_{3}$ film without annealing only pumping away, (e) the top-view SEM image of reference neat $\mathrm{CsPbBr}_{3}$ film which is annealed at $70{ }^{\circ} \mathrm{C}$ for 5 min after pumping away, (f) the absorption and normalized $\mathrm{PL}$ spectra of modified and reference neat $\mathrm{CsPbBr}_{3}$ film. The inset exhibits the $\mathrm{PL}$ intensity of modified and reference neat $\mathrm{CsPbBr}_{3}$ films excited with equal light intensity at $365 \mathrm{~nm}$.

remarkably higher PL intensity compared to the reference neat $\mathrm{CsPbBr}_{3}$ film excited with equal light intensity at $365 \mathrm{~nm}$ (shown in the inset of Fig. 1f). Since the EL efficiency of PeLEDs is proportional to the PL intensity of perovskite, the improvement of PL properties in modified neat $\mathrm{CsPbBr}_{3}$ thin films with only pumping away will be expected to improve the EL efficiency in the modified neat $\mathrm{CsPbBr}_{3}$ thin films based PeLEDs. ${ }^{19}$

\subsection{PeLEDs performance}

Using the modified neat $\mathrm{CsPbBr}_{3}$ film as the light emitter, the PeLEDs exhibit improved EL performance. The PeLEDs employ a typical layered structure of ITO/PEDOT: $\mathrm{PSS}_{30 \mathrm{~nm}} /$ (reference or modified) neat $\mathrm{CsPbBr}_{3}$ film/TPBi ${ }_{65} \mathrm{~nm} / \mathrm{Liq}_{2.5 \mathrm{~nm}} / \mathrm{Al}$. According to the cross-section SEM image of the PeLEDs (Fig. 2a), the thickness of the modified neat $\mathrm{CsPbBr}_{3}$ film is estimated to $\sim 30 \mathrm{~nm}$. The schematic diagram of the PeLEDs structure is shown section SEM image of the neat $\mathrm{CsPbBr}_{3}$ film based PeLEDs. The energy level diagram of each layer is shown in Fig. 2c, and all energy level values were taken from literature. ${ }^{26-28}$ The current density-voltage-luminance $(J-V-L)$ relationship and the current efficiency-voltage-EQE (CE- $V$-EQE) relationship are shown in Fig. $2 \mathrm{~d}$ and e, respectively. From $J-V$ relationship, the modified neat $\mathrm{CsPbBr}_{3}$ film based PeLEDs exhibit lower density than reference film based ones at each applied voltage. It suggests that less current leakage in the modified PeLEDs than that in the reference ones due to higher film coverage and less pinholes in the modified film which is consistent to the top-view SEM results. From the $L-V$ relationship and $\mathrm{CE}-V$-EQE relationship, the modified neat $\mathrm{CsPbBr}_{3}$ film based PeLEDs exhibit higher luminance, current efficiency and EQE than the reference film based ones at each applied voltage, and showing maximum luminance of $3285 \mathrm{~cd}$ $\mathrm{m}^{-2}$, maximum current efficiency of $1.13 \mathrm{~cd} \mathrm{~A}^{-1}$ and maximum EQE of $0.29 \%$, which are 30 times more than that of the PeLEDs with annealing process $\left(70{ }^{\circ} \mathrm{C} / 5 \mathrm{~min}\right)$ showing maximum luminance of $103 \mathrm{~cd} \mathrm{~m}^{-2}$, maximum current efficiency of 0.017 $\mathrm{cd} \mathrm{A}^{-1}$ and maximum EQE of $0.004 \%$. The enhance EL performance can be attributed to both higher film coverage which can make the current leakage decreased ${ }^{\mathbf{1 6}, 26}$ and smaller grain size which can spatially limit the diffusion length of excitons or charge carriers and decrease the possibility of exciton dissociation into carriers. Fig. $2 \mathrm{f}$ shows the EL spectra of modified neat $\mathrm{CsPbBr}_{3}$ film based PeLEDs at different applied voltage, which exhibit a high color purity of FWHM $\sim 18 \mathrm{~nm}$ and a peak wavelength located at $522 \mathrm{~nm}$. In the inset of Fig. 2f, the EL color is stable and the shapes of the EL spectra are independent with applied voltage, which suggest that $\mathrm{CsPbBr}_{3}$ PeLEDs can be potentially adopted as good light sources.

\subsection{Optimizations of PeLEDs}

The improved EL performance of modified film based PeLEDs can be attributed to the higher film coverage and smaller grain size, which are related to the facile and efficient film posttreatment process of only pumping away method. To further investigate the physical mechanism for the enhanced EL performance in $\mathrm{CsPbBr}_{3}$ PeLEDs with only pumping away, both 
(a)

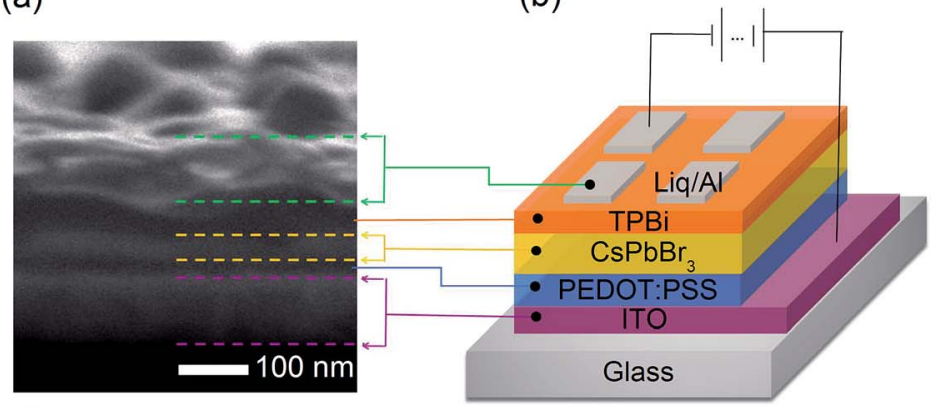

(d) (b)

(e) (c)

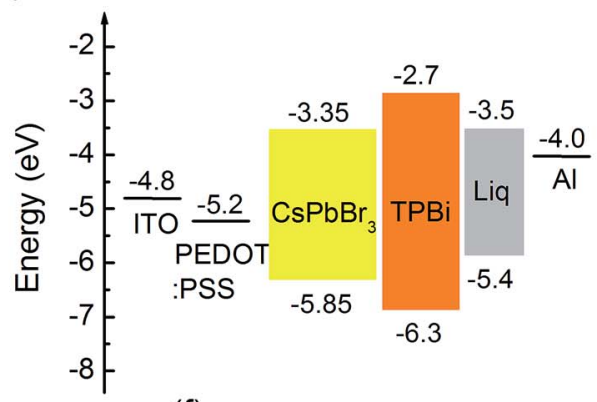

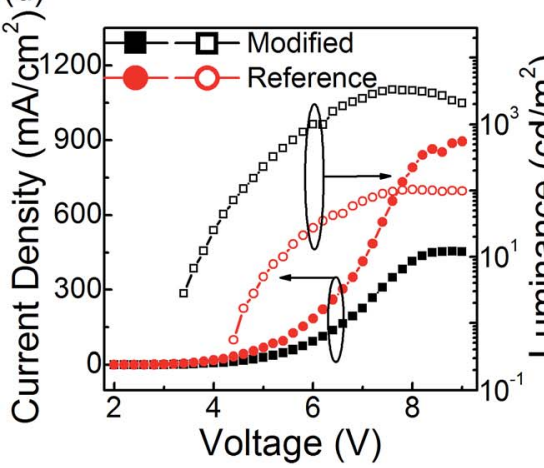

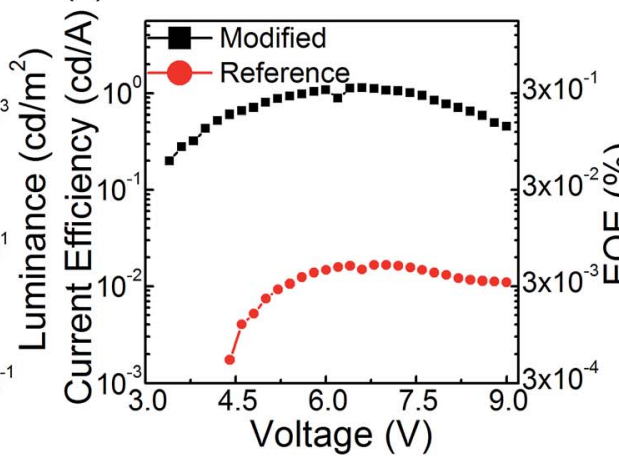

(f)

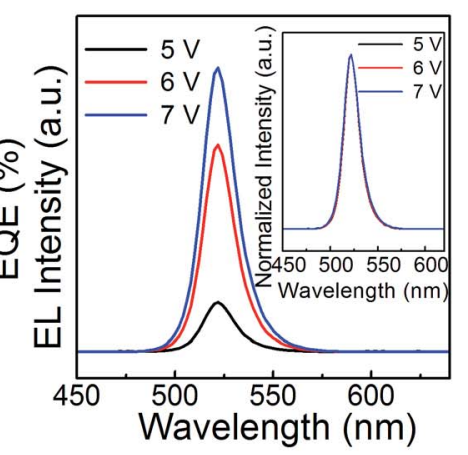

Fig. 2 (a) The cross-section SEM image of the PeLEDs with modified neat $\mathrm{CsPbBr}_{3}$ film, (b) the schematic diagram of the PeLEDs structure, (c) energy level diagram of PeLEDs, (d) $J-V-L$ characteristics of the PeLEDs, (e) CE-V -EQE relationship of the PeLEDs, (f) EL spectra of the PeLEDs based on modified neat $\mathrm{CsPbBr}_{3}$ film applied at different voltages of $5 \mathrm{~V}, 6 \mathrm{~V}$, and $7 \mathrm{~V}$. The inset shows the normalized EL spectra of the modified neat $\mathrm{CsPbBr}_{3}$ film based PeLEDs working at $5 \mathrm{~V}, 6 \mathrm{~V}$, and $7 \mathrm{~V}$.

the optimization of the $\mathrm{CsPbBr}_{3}$ concentration in DMSO precursor solution and the optimization of the molar ratio of $\mathrm{PbBr}_{2}$ to $\mathrm{CsBr}$ will be discussed.

3.3.1 Optimization for the $\mathrm{CsPBBr}_{3}$ concentration. Fig. 3a, $\mathrm{b}$ and $\mathrm{c}$ show the top-view SEM images of modified neat $\mathrm{CsPbBr}_{3}$ films (with only pumping away) deposited from concentrations of $5 \mathrm{wt} \%, 10 \mathrm{wt} \%$, and $15 \mathrm{wt} \%$ in DMSO precursor solution, respectively. For all the films with different concentrations, $\mathrm{CsPbBr}_{3}$ grains are irregular, which are just as same as the published results in ref. 19. It can be found that both the film coverage rate and the size of the grains rise with the increase of $\mathrm{CsPbBr}_{3}$ concentration in DMSO. The coverage rates and grain sizes are estimated to $\sim 49.1 \%$ and $\sim 90 \mathrm{~nm}, \sim 91.1 \%$ and $\sim 100 \mathrm{~nm}, \sim 96.9 \%$ and $\sim 130 \mathrm{~nm}$ for the films with concentrations of $5 \mathrm{wt} \%, 10 \mathrm{wt} \%$ and $15 \mathrm{wt} \%$, respectively. From the $J-V$ relationship (Fig. 3d), $L-V$ relationship (Fig. 3e) and CE- $V$-EQE relationship (Fig. 3f), it can be found that the current density decreases with the increase of $\mathrm{CsPbBr}_{3}$ concentration at each applied voltage, while the PeLEDs based on the $10 \mathrm{wt} \% \mathrm{CsPbBr}_{3}$ film reveals the best EL performance with maximum luminance of $3285 \mathrm{~cd} \mathrm{~m}^{-2}$, maximum current efficiency of $1.13 \mathrm{~cd} \mathrm{~A}^{-1}$, and maximum EQE of $0.29 \%$ (Fig. 3e). Two factors should be take into consideration for the best EL performance in modified $10 \mathrm{wt} \% \mathrm{CsPbBr}_{3}$ film based PeLEDs film coverage and grain size. The coverage rates of modified $\mathrm{CsPbBr}_{3}$ film with concentrations of $10 \mathrm{wt} \%$ are higher than that of modified $\mathrm{CsPBr}_{3}$ film with concentrations of $5 \mathrm{wt} \%$, but lower than that of modified $\mathrm{CsPbBr}_{3}$ film with concentrations of $15 \mathrm{wt} \%$. And grain sizes of modified $\mathrm{CsPbBr}_{3}$ films with concentrations of $10 \mathrm{wt} \%$ are larger than that of modified $\mathrm{CsPbBr}_{3}$ film with concentrations of $5 \mathrm{wt} \%$, but smaller than that of modified $\mathrm{CsPbBr}_{3}$ film with concentrations of $15 \mathrm{wt} \%$. The lower coverage rate makes the current leakage increase, which is bad to the EL performance of PeLEDs, while the smaller grains make the excitons undergo radiative recombination, which is beneficial to the EL performance of PeLEDs. These two aspects compete mutually and the current efficiency (CE) is defined as: $\mathrm{CE}=L / J$, where the $L$ and $J$ represent the luminance and current density at each applied voltage of the PeLEDs, respectively. As a result, the PeLEDs using $10 \mathrm{wt} \% \mathrm{CsPbBr}_{3}$ film exhibit the best $\mathrm{EL}$ performance with suitable coverage rate and grain size. Meanwhile, for the PeLEDs using $5 \mathrm{wt} \% \mathrm{CsPbBr}_{3}$ film show a greater current density at each applied voltage and an inferior EL performance compared to PeLEDs based on $10 \mathrm{wt} \% \mathrm{CsPbBr}_{3}$ film, which suggests that the lower coverage rate plays a leading role in weakening the EL performance in $5 \mathrm{wt} \% \mathrm{CsPbBr}_{3}$ film based PeLEDs. When it comes to the PeLEDs using $15 \mathrm{wt} \%$ $\mathrm{CsPbBr}_{3}$ film, it exhibits a lower current density at each applied voltage and an inferior EL performance compared to PeLEDs based on $10 \mathrm{wt} \% \mathrm{CsPbBr}_{3}$ film, which suggests that larger grain size plays a leading role to reduce the current efficiency in the PeLEDs with $15 \mathrm{wt} \% \mathrm{CsPbBr}_{3}$ film.

3.3.2 Optimization for the molar ratio of $\mathrm{PbBr}_{2}$ to $\mathrm{CsBr}$. Besides optimization for the $\mathrm{CsPbBr}_{3}$ concentration in DMSO precursor solution, the PeLEDs with different molar ratios of $\mathrm{PbBr}_{2}$ to $\mathrm{CsBr}$ equaling to $1.1: 1,1: 1,1: 1.2$, and $1: 1.4$ at 
(a)
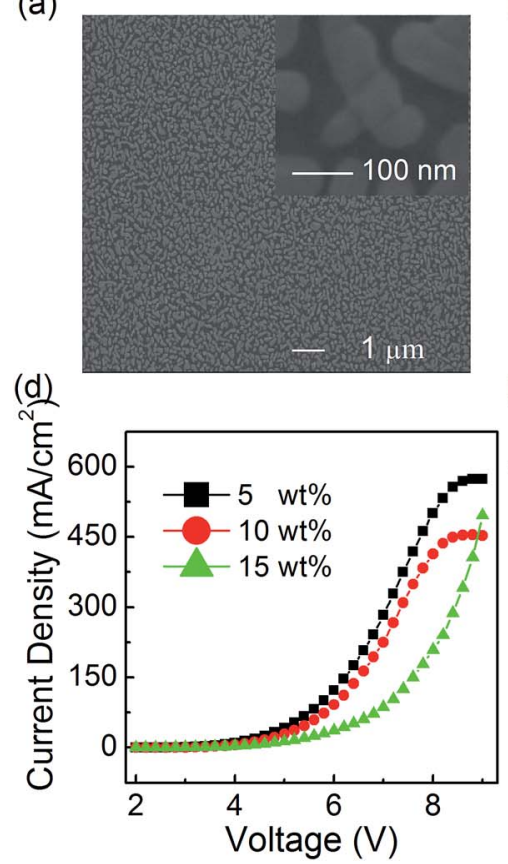

(b)

(e)

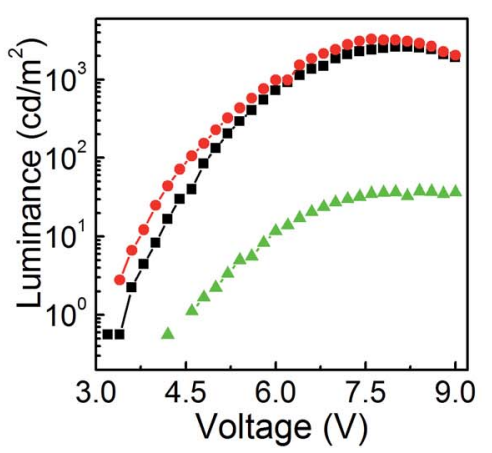

(c)

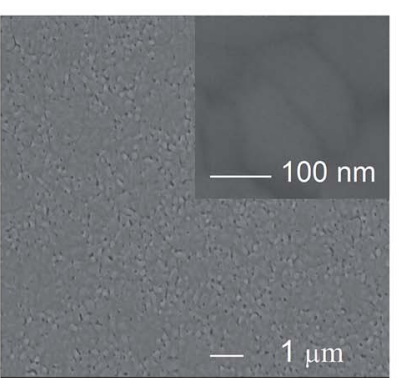

(f)

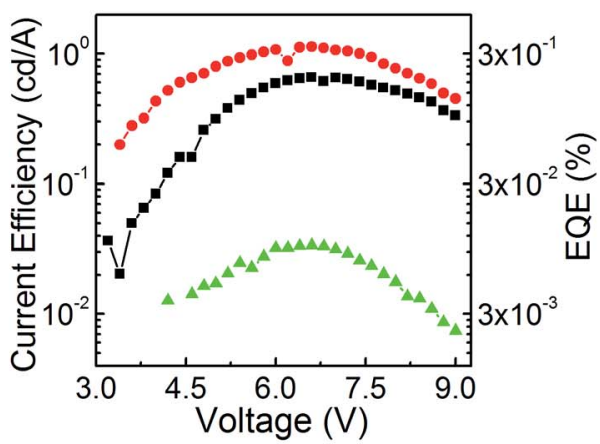

Fig. 3 The top-view SEM image of modified neat $\mathrm{CsPbBr}_{3}$ film with only pumping away from different concentrations of (a) 5 wt\%, (b) 10 wt\%, (c) $15 \mathrm{wt} \%$ in DMSO precursor solution, (d) $J-V-L$ relationship, (e) $L-V$ of the PeLEDs, (f) CE- $V$-EQE relationship of the PeLEDs based on different $\mathrm{CsPbBr}_{3}$ concentrations in DMSO precursor solution.

(a)

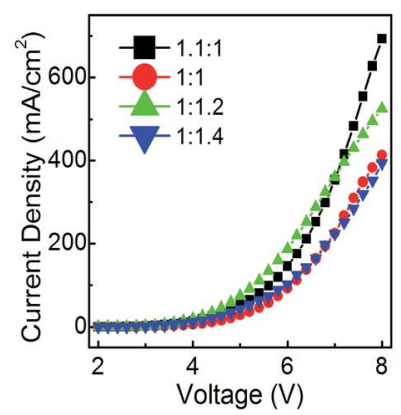

(b)

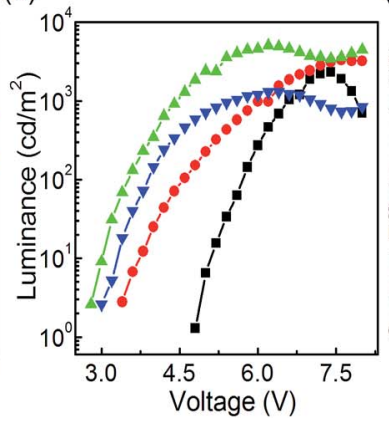

(c)

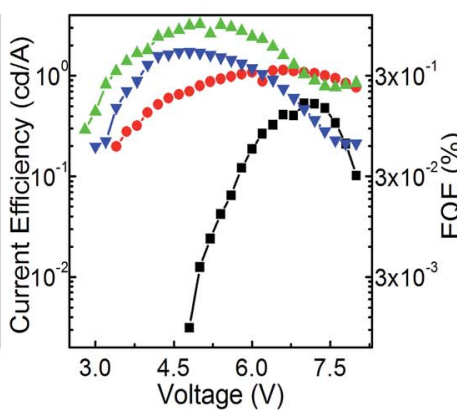

(d)

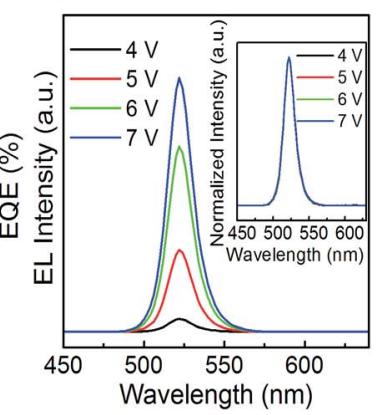

Fig. 4 (a) J-V relationship, (b) $L-V$ relationship, (c) CE-V-EQE relationship of the PeLEDs with only pumping away and different molar ratios of $\mathrm{PbBr}_{2}$ to $\mathrm{CsBr}$ of $1.1: 1,1: 1,1: 1.2$, and $1: 1.4$ at a 10 wt\% $\mathrm{CsPbBr}_{3}$ concentration in DMSO precursor solution, (d) EL spectra of the PeLEDs based on modified neat $\mathrm{CsPbBr}_{3}$ film molar ratio of $\mathrm{PbBr}_{2}$ to $\mathrm{CsBr}$ of $1: 1.2$ at a $10 \mathrm{wt} \% \mathrm{CsPbBr}_{3}$ concentration in DMSO precursor solution with applied at different voltages of $4 \mathrm{~V}, 5 \mathrm{~V}, 6 \mathrm{~V}$, and $7 \mathrm{~V}$. The inset shows the normalized EL spectra of the modified neat $10 \mathrm{wt} \% \mathrm{CsPbBr} 3 \mathrm{PeLEDs}$ based on the molar ratio of $\mathrm{PbBr}_{2}$ to $\mathrm{CsBr}$ equaling to $1: 1.2$ working at $4 \mathrm{~V}, 5 \mathrm{~V}, 6 \mathrm{~V}$, and $7 \mathrm{~V}$.

a $10 \mathrm{wt} \% \mathrm{CsPBr}_{3}$ concentration in DMSO precursor solution are fabricated with only pumping away process. From the $J-V$ curves, the PeLEDs based on the molar ratio of $\mathrm{PbBr}_{2}$ to $\mathrm{CsBr}$ equaling to $1: 1.2$ exhibit the largest current density among all PeLEDs at each applied voltage lower than $7 \mathrm{~V}$. When it comes to the $L-V$ relationship, the PeLEDs with a molar ratio of $\mathrm{PbBr}_{2}$ to $\mathrm{CsBr}$ of $1: 1.2$ exhibit the highest maximum luminance of $5046 \mathrm{~cd} \mathrm{~m}^{-2}$ and lowest turn on voltage of $2.8 \mathrm{~V}$ among all the devices. Moreover, the current efficiency and EQE of the PeLEDs with a molar ratio of $\mathrm{PbBr}_{2}$ to $\mathrm{CsBr}$ equaling to $1: 1.2$ show the best with maximum current efficiency of $3.25 \mathrm{~cd} \mathrm{~A}^{-1}$ and maximum EQE of $0.85 \%$ among all the devices, which is among the best results based on neat $\mathrm{CsPbBr}_{3}$ PeLEDs reported so far. It should be noted that the maximum current efficiency and the maximum EQE of PeLEDs increase with the CsBr proportion increasing in all the PeLEDs. This enhancement in EL performance is attributed to the Br-rich passivation that can reduce the halogen vacancies $\left(\mathrm{V}_{\mathrm{Br}}\right)$ (e.g. decreasing the non-radiative recombination), and thus leading to improved EL performance. This is verified by previous theoretical ${ }^{29}$ studying. Previous theoretical density functional theory (DFT) demonstrate that the presence of $\mathrm{V}_{\mathrm{Br}}$ on $\mathrm{CsPbBr}_{3}$ plays a role as defects within the band gap and acts as recombination centers. The deposition from CsBr-rich solution may reduce the probability 


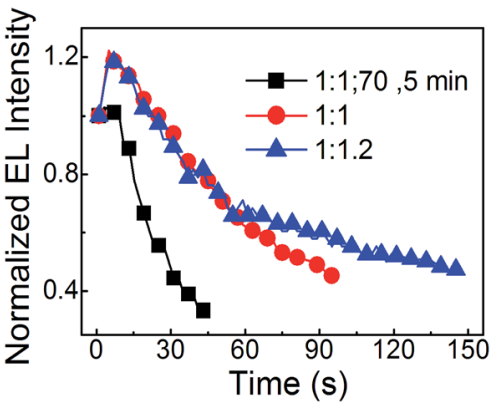

Fig. 5 The stability of PeLEDs formed by $\mathrm{PbBr}_{2}: \mathrm{CsBr}=1: 1$ with annealing at $70{ }^{\circ} \mathrm{C}$ for 5 min after pumping away, $\mathrm{PbBr}_{2}: \mathrm{CsBr}=1: 1$ with just pumping away, and $\mathrm{PbBr}_{2}: \mathrm{CsBr}=1: 1.2$ with just pumping away.

of $\mathrm{V}_{\mathrm{Br}}$ formation on the films and hence reduce the nonradiative defect densities. And this is demonstrated by previous experimental ${ }^{19}$ and the time-resolved PL measurements we conducted. The time-resolved PL spectra are exhibited in the Fig. S2. $\dagger$ The average radiative recombination lifetime of the $1: 1.2$ neat $\mathrm{CsPbBr}_{3}$ films ( $\left.0.86 \mathrm{~ns}\right)$ with only pumping away is larger than $1: 1$ neat $\mathrm{CsPbBr}_{3}$ films (0.82 ns). The result suggests that $\mathrm{Br}$ additive can effectively passivate the grain boundaries, and thus reducing non-radiation recombination, leading to enhanced the EL performance in the $1: 1.2$ neat $\mathrm{CsPbBr}_{3}$ films based PeLEDs. And the PeLEDs with molar ratio of $1: 1.2$ also show stable color with a high color purity of FWHM $\sim 18 \mathrm{~nm}$ and a peak wavelength located at $522 \mathrm{~nm}$ at different applied voltages (show in Fig. $4 \mathrm{~d}$ and its inset).

3.3.3 The stability of PeLEDs. As shown in Fig. 5, the stability of both equal molar ratio of $\mathrm{PbBr}_{2}$ : $\mathrm{CsBr}$ and $\mathrm{CsBr}$ rich $\left(\mathrm{PbBr}_{2}: \mathrm{CsBr}=1: 1.2\right)$ neat $\mathrm{CsPbBr}_{3}$ PeLEDs with just pumping away are better than that of neat $\mathrm{CsPbBr}_{3}$ PeLEDs with annealing. The half lifetimes (which is the time duration from the initial luminance of $100 \mathrm{~cd} \mathrm{~m}^{-2}$ decreasing to half luminance of the initial luminance) of the three PeLEDs formed by $\mathrm{PbBr}_{2}: \mathrm{CsBr}=1: 1$ with annealing at $70{ }^{\circ} \mathrm{C}$ for 5 min after pumping away, $\mathrm{PbBr}_{2}: \mathrm{CsBr}=1: 1$ with just pumping away, and $\mathrm{PbBr}_{2}: \mathrm{CsBr}=1: 1.2$ with just pumping away are estimated to $29 \mathrm{~s}, 87 \mathrm{~s}$ and $135 \mathrm{~s}$, respectively. It indicates that the

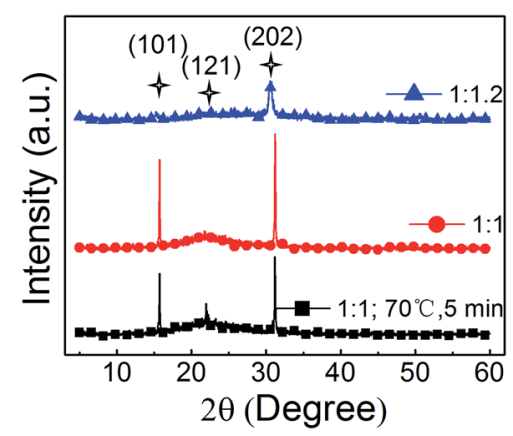

Fig. 6 The XRD patterns of three $10 \mathrm{wt} \%$ neat $\mathrm{CsPbBr}_{3}$ films $\left(\mathrm{PbBr}_{2}: \mathrm{CsBr}=1: 1\right.$ with annealing at $70{ }^{\circ} \mathrm{C}$ for 5 min after pumping away, $\mathrm{PbBr}_{2}: \mathrm{CsBr}=1: 1$ with just pumping away, $\mathrm{PbBr}_{2}: \mathrm{CsBr}=$ $1: 1.2$ with just pumping away).

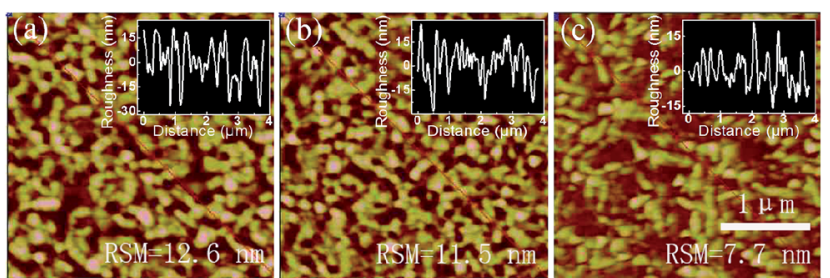

Fig. 7 AFM images for three 10 wt\% neat $\mathrm{CsPbBr}_{3}$ films (a) $\mathrm{PbBr}_{2}: \mathrm{CsBr}$ $=1: 1$ with annealing at $70{ }^{\circ} \mathrm{C}$ for $5 \mathrm{~min}$ after pumping away, (b) $\mathrm{PbBr}_{2}: \mathrm{CsBr}=1: 1$ with just pumping away, (c) $\mathrm{PbBr}_{2}: \mathrm{CsBr}=1: 1.2$ with just pumping away.

pumping away process and the $\mathrm{Br}$ rich method are benefit to make the PeLEDs more stable.

\subsection{XRD patterns of perovskite films}

In Fig. 6, the XRD patterns of the three neat $\mathrm{CsPbBr}_{3}$ films $\left(\mathrm{PbBr}_{2}: \mathrm{CsBr}=1: 1\right.$ with annealing at $70{ }^{\circ} \mathrm{C}$ for 5 min after pumping away, $\mathrm{PbBr}_{2}: \mathrm{CsBr}=1: 1$ with just pumping away, $\mathrm{PbBr}_{2}: \mathrm{CsBr}=1: 1.2$ with just pumping away) indicate that orthorhombic crystal structures are realized. And no additional peak for the solvent residue are found in the XRD patterns, which means that there is no solvent residue in all the three films. To further confirm it, the UV-Vis absorption spectra are shown in Fig. S3, $\uparrow$ and similar absorption shapes are demonstrated. These results suggest that the structures and the optical properties of perovskite films with just pumping away are same with that of the one with annealing, which may not do bad effects to the EL performance.

\subsection{AFM images of perovskite films}

AFM images are performed and are shown in Fig. 7. For the neat $1: 1 \mathrm{CsPbBr}_{3}$ films, the annealed one exhibits a larger roughness of $12.6 \mathrm{~nm}$ compared to the one without annealing $(11.5 \mathrm{~nm})$, which indicating that annealing after the pumping away process will do bad effect to the morphology of the perovskite film and leading to worse EL performance of the PeLED with annealed neat $1: 1 \mathrm{CsPbBr}_{3}$ film. And with only pumping away process, the surface roughness can be further reduced to $7.7 \mathrm{~nm}$ by $\mathrm{Br}$ rich $\mathrm{CsPbBr}_{3}$ film with $\mathrm{PbBr}_{2}$ : $\mathrm{CsBr}$ equaling to $1: 1.2$. Thus, with the smoothest $\mathrm{CsPbBr}_{3}$ film, the PeLEDs with molar ratio of $1: 1.2$ achieved the best EL performance.

\section{Conclusion}

The simple and effective method of only pumping away process is demonstrated to fabricate equimolar and $\mathrm{CsBr}$-rich $\mathrm{CsPbBr}_{3}$ PeLEDs with enhanced EL performance of maximum luminance of $3285 \mathrm{~cd} \mathrm{~m}^{-2}$ and $5046 \mathrm{~cd} \mathrm{~m}^{-2}$, maximum current efficiency of $1.13 \mathrm{~cd} \mathrm{~A}^{-1}$ and $3.25 \mathrm{~cd} \mathrm{~A}^{-1}$ and EQE of $0.29 \%$ and $0.85 \%$, which are 30 folds more than that of the equimolar ones with $70{ }^{\circ} \mathrm{C} / 5 \mathrm{~min}$ annealing process after pumping away process. The only pumping away process benefits to obtain high quality $\mathrm{CsPbBr}_{3}$ film with higher coverage, smaller grains better Br-rich passivation, and smoother surface, which lead to less 
current leakage, and larger possibility of exciton radiative decay, and thus achieving better EL performance and longer stability in PeLEDs with only pumping away. The work therefore offers some helpful implications in developing high-performance PeLEDs.

\section{Conflicts of interest}

There are no conflicts of interest to declare.

\section{Acknowledgements}

We acknowledge financial support from the Natural Science Foundation of China (Grant No. 61404108, 11504300 and 11374242), and Fundamental Research Funds for the Central Universities (Grant No. XDJK2017D140). And authors thank for Prof. Guo-Qing Li, Prof. Hu-Zhi Zheng, and Prof. Yuan-Fang Li (Southwest University) for their help related to experiments and fruitful discussions.

\section{Notes and references}

1 Z. K. Tan, R. S. Moghaddam, M. L. Lai, P. Docampo, R. Higler, F. Deschler, M. Price, A. Sadhanala, L. M. Pazos, D. Credgington, F. Hanusch, T. Bein, H. J. Snaith and R. H. Friend, Nat. Nanotechnol., 2014, 9, 687-692.

2 G. R. Li, F. W. R. Rivarola, N. J. L. K. Davis, S. Bai, T. C. Jellicoe, F. D. L. Pena, S. C. Hou, C. Ducati, F. Gao, R. H. Friend, N. C. Greenham and Z. K. Tan, Adv. Mater., 2016, 28, 3528-3534.

3 M. Kulbak, D. Cahen and G. Hodes, J. Phys. Chem. Lett., 2015, 6, 2452-2456.

4 F. Palazon, F. D. Stasio, Q. A. Akkerman, R. Krahne, M. Prato and L. Manna, Chem. Mater., 2016, 28, 2902-2906.

5 C. C. Stoumpos, C. D. Malliakas, J. A. Peters, Z. F. Liu, M. Sebastian, J. Im, T. C. Chasapis, A. C. Wibowo, D. Y. Chung, A. J. Freeman, B. W. Wessels and M. G. Kanatzidis, Cryst. Growth Des., 2013, 13, 2722-2727.

6 S. Colella, M. Mazzeo, A. Rizzo, G. Gigli and A. Listorti, J. Phys. Chem. Lett., 2016, 7, 4322-4334.

7 X. M. Li, Y. Wu, S. L. Zhang, B. Cai, Y. Gu, J. Z. Song and H. B. Zeng, Adv. Funct. Mater., 2016, 26, 2435-2445.

8 G. P. Li, H. Wang, T. Zhang, L. F. Mi, Y. G. Zhang, Z. P. Zhang, W. J. Zhang and Y. Jiang, Adv. Funct. Mater., 2016, 26, 84788486.

9 Y. H. Kim, H. Cho and T. W. Lee, Proc. Natl. Acad. Sci. U. S. A., 2016, 113, 11694-11702.
10 H. Cho, S. H. Jeong, M. H. Park, Y. H. Kim, C. Wolf, C. L. Lee, J. H. Heo, A. Sadhanala, N. S. Myoung, S. Yoo, S. H. Im, R. H. Friend and T. W. Lee, Science, 2015, 350, 1222-1225.

11 J. Z. Song, J. H. Li, X. M. Li, L. M. Xu, Y. H. Dong and H. B. Zeng, Adv. Mater., 2015, 27, 7162-7167.

12 Y. H. Song, J. S. Yoo, B. K. Kang, S. H. Choi, E. K. Ji, H. S. Jung and D. H. Yoon, Nanoscale, 2016, 8, 19523-19526.

13 X. L. Zhang, B. Xu, J. B. Zhang, Y. Gao, Y. J. Zheng, K. Wang and X. W. Sun, Adv. Funct. Mater., 2016, 26, 4595-4600.

14 H. Huang, H. Lin, S. V. Kershaw, A. S. Susha, W. C. H. Choy and A. L. Rogach, J. Phys. Chem. Lett., 2016, 7, 4398-4404.

15 X. Y. Zhang, H. Lin, H. Huang, C. Reckmeier, Y. Zhang, W. C. H. Choy and A. L. Rogach, Nano Lett., 2016, 16, 1415-1420.

16 J. Q. Li, X. Shan, S. G. R. Bade, T. Geske, Q. L. Jiang, X. Yang and Z. B. Yu, J. Phys. Chem. Lett., 2016, 7, 4059-4066.

17 X. Y. Zhang, C. Sun, Y. Zhang, H. Wu, C. Y. Ji, Y. H. Chuai, P. Wang, S. P. Wen, C. F. Zhang and W. W. Yu, J. Phys. Chem. Lett., 2016, 7, 4602-4610.

18 J. H. Li, L. M. Xu, T. Wang, J. Z. Song, J. W. Chen, J. Xue, Y. H. Dong, B. Cai, Q. S. Shan, B. N. Han and H. B. Zeng, Adv. Mater., 2017, 29, 1603885.

19 N. Yantara, S. Bhaumik, F. Yan, D. Sabba, H. A. Dewi, N. Mathews, P. P. Boix, H. V. Demir and S. Mhaisalkar, J. Phys. Chem. Lett., 2015, 6, 4360-4364.

20 Y. C. Ling, Y. Tian, X. Wang, J. C. Wang, J. M. Knox, F. PerezOrive, Y. J. Du, L. Tan, K. Hanson, B. W. Ma and H. W. Gao, Adv. Mater., 2016, 28, 8983-8989.

21 L. Song, X. Y. Guo, Y. S. Hu, Y. Lv, J. Lin, Z. Q. Liu, Y. Fan and X. Y. Liu, J. Phys. Chem. Lett., 2017, 8, 4148-4154.

22 Z. H. Wei, A. Perumal, R. Su, S. Sushant, J. Xing, Q. Zhang, S. T. Tan, H. V. Demir and Q. H. Xiong, Nanoscale, 2016, 8, 18021-18026.

23 G. R. Li, M. Price and F. Deschler, APL Mater., 2016, 4, 091507.

24 L. Protesescu, S. Yakunin, M. I. Bodnarchuk, F. Krieg, R. Caputo, C. H. Hendon, R. X. Yang, A. Walsh and M. V. Kovalenko, Nano Lett., 2015, 15, 3692-3696.

25 H. C. Yoon, H. Kang, S. Lee, J. H. Oh, H. Yang and Y. R. Do, ACS Appl. Mater. Interfaces, 2016, 8, 18189-18200.

26 P. Chen, Z. Y. Xiong, X. Y. Wu, M. Shao, X. J. Ma, Z. H. Xiong and C. H. Gao, J. Phys. Chem. Lett., 2017, 8, 1810-1818.

27 S. I. Yoo, J. A. Yoon, N. H. Kim, J. W. Kim, J. S. Kang, C. B. Moon and W. Y. Kim, J. Lumin., 2015, 160, 346-350.

28 V. K. Ravi, G. B. Markad and A. Nag, ACS Energy Lett., 2016, 1, 665-671.

29 H. L. Shi and M. H. Du, Phys. Rev. B: Condens. Matter Mater. Phys., 2014, 90, 174103. 